\title{
Acquired Fanconi syndrome in a dog exposed to jerky treats in Japan
}

\author{
Masaya IGASE ${ }^{2)}$, Kenji BABA ${ }^{1) *}$, Takako SHIMOKAWA MIYAMA ${ }^{1)}$, Shunsuke NOGUCHI'), Takuya MIZUNO2) \\ and Masaru OKUDA ${ }^{1)}$ \\ ${ }^{1)}$ Laboratory of Veterinary Internal Medicine, Joint Faculty of Veterinary Medicine, Yamaguchi University, Yamaguchi 753-8515, Japan \\ ${ }^{2)}$ Laboratory of Molecular Diagnostics and Therapeutics, Joint Faculty of Veterinary Medicine, Yamaguchi University, Yamaguchi \\ 753-8515, Japan
}

(Received 25 March 2015/Accepted 27 May 2015/Published online in J-STAGE 11 June 2015)

ABSTRACT. A 6-year-old spayed female Jack Russell Terrier presented with a 1-month history of lethargy, anorexia, vomiting and weight loss. The dog was fed beef and chicken jerky treats daily in addition to a commercial diet. Laboratory tests revealed azotemia, hypokalemia, hyperchloremia, metabolic acidosis and glucosuria with normoglycemia. Urine amino acid analysis showed significant amino acid loss into the urine. Thus, Fanconi syndrome was diagnosed, and based on the case history and extensive diagnostic testing, excessive consumption of jerky treats was strongly suspected as the cause. Glucosuria resolved 7 days after the withdrawal of jerky treats and fluid therapy. Aminoaciduria was substantially, but not completely, improved 3 months after diagnosis. Mild azotemia remained, suggesting chronic renal disease. To the best of our knowledge, this is the first reported case of Fanconi syndrome following the consumption of jerky treats in Japan. KEY WORDS: aminoaciduria, canine, Fanconi syndrome, Japan, jerky treat

doi: 10.1292/jvms.15-0180; J. Vet. Med. Sci. 77(11): 1507-1510, 2015

Fanconi syndrome is characterized by impaired reabsorptive function of the proximal renal tubule, resulting in excessive loss of water, glucose, amino acids, uric acid, phosphate, bicarbonate and other electrolytes [2]. Inherited Fanconi syndrome has been well documented in Basenji dogs [16], whereas acquired Fanconi syndrome is rarely recognized in dogs. Previously reported cases of acquired Fanconi syndrome occurred in dogs with hepatic copper toxicosis, leptospirosis, primary hypoparathyroidism and hereditary renal disease $[1,7-10]$. Acquired Fanconi syndrome has also been associated with exposure to ethylene glycol, streptozotocin, antibiotics and more recently, chicken jerky treats $[3,4,11,12,14,18,20]$. Since 2007, the Food and Drug Administration (FDA) has warned of a potential association between illness and consumption of chicken jerky treats [6]. Nonspecific signs have been noted, including lethargy, anorexia, vomiting, diarrhea and polyuria/polydipsia. Laboratory testing may reveal renal failure, glucosuria with normoglycemia, metabolic acidosis and generalized aminoaciduria, indicating Fanconi syndrome. Cases of Fanconi syndrome associated with chicken jerky treats have been documented in North America, Australia and Europe, but not in Asia [4, 11, 12, 20]. Notably, in almost all cases, dogs have consumed chicken jerky treats with ingredients from China. Given the global distribution of pet food products, the increase in the number of cases is worrisome worldwide.

*Correspondence to: BabA, K., Laboratory of Veterinary Internal Medicine, Joint Faculty of Veterinary Medicine, Yamaguchi University, 1677-1 Yoshida, Yamaguchi 753-8515, Japan.

e-mail:kbaba@yamaguchi-u.ac.jp

(C)2015 The Japanese Society of Veterinary Science

This is an open-access article distributed under the terms of the Creative Commons Attribution Non-Commercial No Derivatives (by-nc-nd) License $<$ http://creativecommons.org/licenses/by-nc-nd/3.0/>.
The present report describes the clinical features and treatment outcomes of a dog in Japan with Fanconi syndrome after consuming jerky treats, some of which contained ingredients from China.

A 6-year-old spayed female Jack Russell Terrier, weighing $5.4 \mathrm{~kg}$, was referred to Yamaguchi University Animal Medical Center for evaluation of a 1-month history of lethargy, anorexia, vomiting and weight loss. These clinical signs were not resolved after general management at the local animal hospital. Two days before the initial visit, azotemia, hypokalemia and glucosuria were measured at the local animal hospital. The dog was fed different beef and chicken jerky treats daily, some of which contained ingredients from China, in addition to a commercial diet. Once anorexia was observed, much of her diet had been jerky treats for 1 month, as a result of her dietary preferences.

At the time of initial presentation, a blood test revealed normal complete blood cell count $(\mathrm{CBC})$ and increased blood urea nitrogen (BUN) $(119.8 \mathrm{mg} / \mathrm{d} l$; reference range, $9.2-29.2 \mathrm{mg} / \mathrm{d} l)$ and creatinine $(2.4 \mathrm{mg} / \mathrm{d} l$; reference range, $0.4-1.4 \mathrm{mg} / \mathrm{d} l)$. In addition, hypokalemia $(2.1 \mathrm{mEq} / l$; reference range, $3.8-5.0 \mathrm{mEq} / l)$ and hyperchloremia $(122 \mathrm{mEq} / l$; reference range, $102-117 \mathrm{mEq} / l)$ were also revealed. Blood glucose was within the normal range $(95 \mathrm{mg} / \mathrm{d} l$; reference range, $75-128 \mathrm{mg} / \mathrm{d} l$ ). Urinalysis showed a specific gravity of 1.038, a $\mathrm{pH}$ of 6.0 , moderate glucosuria $(250 \mathrm{mg} /$ $\mathrm{d} l$, determined by dipstick) and trace proteinuria $(30 \mathrm{mg} /$ $\mathrm{d} l$, determined by dipstick). Urine protein/creatinine ratio was 0.42 (reference range, $<0.5$ ). Urine sediment identified epithelial and granular casts without hematuria, pyuria or bacteriuria. Venous blood gas analysis showed metabolic acidosis with a $\mathrm{pH}$ of 7.292 (reference range, 7.35-7.45), a venous $\mathrm{CO}_{2}$ pressure $\left(\mathrm{PvCO}_{2}\right)$ of $32.7 \mathrm{~mm} \mathrm{Hg}$ (reference range, $40-50 \mathrm{~mm} \mathrm{Hg}$ ), a bicarbonate concentration of $15.4 \mathrm{mmol} / l$ (reference range, $20-24 \mathrm{mmol} / l$ ) and a base ex- 
Table 1. Urine amino acids and derivatives profile

$(\mathrm{mmol} / \mathrm{g} \cdot \mathrm{cre})^{*}$

\begin{tabular}{|c|c|c|c|}
\hline Substance & Initial visit & Three months after & Reference value** \\
\hline Taurine & 173.4 & $1,988.9$ & $7,049.4 \pm 3,439.1$ \\
\hline Phosphorthanol-amine & 70.1 & 201.2 & $60.9 \pm 48.7$ \\
\hline Aspartic acid & 3.4 & 14.1 & $5.9 \pm 3.4$ \\
\hline Hydroxyproline & 211.2 & 153.4 & ND \\
\hline Threonine & $4,587.4$ & 659.2 & $79.9 \pm 88.1$ \\
\hline Serine & $1,531.5$ & 267.7 & $126.6 \pm 30.5$ \\
\hline Asparagine & 851.9 & 98.3 & $29.9 \pm 25.8$ \\
\hline Glutamic acid & 122.9 & 44.2 & $25.9 \pm 12.9$ \\
\hline Glutamine & $11,874.9$ & 635.7 & $98.7 \pm 47.3$ \\
\hline Sarcosine & 28.2 & 306.0 & ND \\
\hline$\alpha$-Aminoadipic acid & 166.3 & 96.6 & $32.0 \pm 19.2$ \\
\hline Proline & 173.4 & 203.9 & ND \\
\hline Glycine & $3,544.5$ & 396.4 & $68.7 \pm 31.3$ \\
\hline Alanine & $6,077.1$ & 583.9 & $192.3 \pm 103.7$ \\
\hline Citrulline & $1,956.7$ & 503.5 & $27.1 \pm 12.9$ \\
\hline$\alpha$-Amino-n-butyric acid & 250.2 & 9.1 & $2.3 \pm 1.1$ \\
\hline Valine & 373.9 & 90.1 & $21.3 \pm 5.1$ \\
\hline Cystine & 633.6 & 114.4 & $27.6 \pm 9.7$ \\
\hline Methionine & 57.9 & 244.6 & $45.3 \pm 56.9$ \\
\hline Cystathionine & 251.9 & 356.8 & $11.2 \pm 10.0$ \\
\hline Isoleucine & 123.4 & 2.4 & $5.5 \pm 2.3$ \\
\hline Leucine & 185.4 & 12.7 & $39.4 \pm 18.2$ \\
\hline Tyrosine & 552.1 & 12.5 & ND \\
\hline Phenylalanine & 247.4 & 5.3 & $4.3 \pm 1.3$ \\
\hline$\beta$-Alanine & 25.4 & 60.8 & $72.6 \pm 44.4$ \\
\hline$\beta$-Amino-iso-butyric acid & 45.3 & 136.8 & $31.8 \pm 16.7$ \\
\hline Homocystine & 40.6 & ND & ND \\
\hline$\gamma$-Amino-n-butyric acid & ND & ND & ND \\
\hline Ethanolamine & 149.1 & 150.7 & $91.8 \pm 10.7$ \\
\hline Hydroxylysin & 6.7 & ND & ND \\
\hline Ornithine & 108.1 & 26.0 & $12.1 \pm 7.1$ \\
\hline Tryptophan & 316.1 & 11.5 & $5.9 \pm 5.1$ \\
\hline Lysine & 423.8 & 51.5 & $44.0 \pm 18.7$ \\
\hline 1-Methyl-histidine & 516.7 & 522.3 & $688.1 \pm 493.1$ \\
\hline Histidine & $1,567.3$ & 118.8 & $19.1 \pm 2.8$ \\
\hline 3-Methyl-histidine & 384.8 & 265.8 & $177.1 \pm 40.5$ \\
\hline Anserine & ND & ND & ND \\
\hline Carnosine & 10.1 & ND & ND \\
\hline Arginine & 97.7 & 54.2 & $17.4 \pm 6.9$ \\
\hline
\end{tabular}

*The concentrations of amino acids and derivatives $(\mathrm{mmol} / l)$ were calibrated by the concentration of creatinine $(\mathrm{g} / l)$.**The reference values were calculated as average \pm 2 standard deviation of the concentrations of amino acids and derivatives in 3 healthy dogs. ND: Not detected

cess $(\mathrm{BE})$ of $-9.9 \mathrm{mmol} / l$ (reference range, -4 to $+4 \mathrm{mmol} / l$ ). No significant abnormalities were observed on radiography and abdominal ultrasonography.

Because of the suspicion of Fanconi syndrome, a spot urine sample was submitted for amino acids and derivatives analysis by high performance liquid chromatography (Bio Medical Laboratories, Saitama, Japan). To correct for the influence of urinary concentration or dilution in spot urine samples, the urinary excretions of amino acids and derivatives were adjusted for the urinary creatinine concentration ( $\mu \mathrm{mol} / \mathrm{g}$ of creatinine) as described previously [22]. Because reference values for the urine amino acids and derivatives profile had not been established, the measured value was compared with that of three healthy dogs. Increased excretion of most amino acids was found, but not all amino acids and derivatives were lost equally (Table 1). Given glucosuria in the absence of hyperglycemia, metabolic acidosis and generalized aminoaciduria, a diagnosis of Fanconi syndrome was established.

The possible cause of Fanconi syndrome was carefully explored. Medications associated with acquired Fanconi syndrome, such as antibiotics, nonsteroidal anti-inflammatory drugs and cyclosporine, had not been administered prior to onset of clinical signs. It was highly unlikely that the dog was exposed to environmental toxins, such as cadmium, lead and mercury, according to the dog's history and life 
circumstances. Hepatic copper toxicosis and primary hypoparathyroidism were excluded by the absence of hepatic insufficiency and hypocalcemia, respectively. Titers for Leptospira interrogans(serovars canicola, icterohaemorrhagiae and hebdomadis) were examined and eventually reported as negative. In humans, Fanconi syndrome may result from tubular injury related to urinary excretion of abnormal proteins, such as multiple myeloma and amyloidosis [13, 17]. In the dog, multiple myeloma was excluded by the absence of hyperproteinemia and osteolytic bone lesions. Amyloidosis was also excluded by the absence of proteinuria, although a renal biopsy was not performed. Urinary tract infection and pyelonephritis could not be definitively excluded, because a urine culture was not performed; however, they were highly unlikely as the cause of Fanconi syndrome in the dog, because pyuria and bacteriuria were not observed in the urine sediment. On the basis of the case history and findings, the excess consumption of jerky treats was strongly suspected as the cause of Fanconi syndrome.

The dog was hospitalized and treated with acetated Ringer's solution with $40 \mathrm{mEq} / \mathrm{l}$ of potassium chloride. The dog was also treated with potassium sodium hydrogen citrate (Uralyte ${ }^{\circledR}, 231.5 \mathrm{mg}$ of potassium citrate and 195 $\mathrm{mg}$ of sodium hydrogen citrate, PO, BID), famotidine $(0.5$ $\mathrm{mg} / \mathrm{kg}, \mathrm{IV}, \mathrm{SID})$ and metronidazole (11 mg/kg, PO, BID). The jerky treats were immediately withdrawn. On day 2 of hospitalization, BUN $(78.5 \mathrm{mg} / \mathrm{d} l)$, creatinine $(2.1 \mathrm{mg} /$ $\mathrm{d} l)$, potassium $(3.0 \mathrm{mEq} / l)$ and chloride $(122 \mathrm{mEq} / l)$ levels were measured. Metabolic acidosis was resolved $(\mathrm{pH}$, 7.402; $\mathrm{PvCO}_{2}, 36.9 \mathrm{~mm} \mathrm{Hg}$; bicarbonate, $22.5 \mathrm{mmol} / l$; and BE, -1.9). Glucosuria was still present, but it mildly improved (100 $\mathrm{mg} / \mathrm{d} l$, determined by dipstick). On day 3 of hospitalization, BUN $(49.2 \mathrm{mg} / \mathrm{d} l)$, creatinine $(1.9 \mathrm{mg} /$ $\mathrm{d} l$ ), potassium $(2.9 \mathrm{mEq} / l)$ and chloride $(119 \mathrm{mEq} / l)$ levels were measured again. Metabolic acidosis continued to improve $\left(\mathrm{pH}, 7.393 ; \mathrm{PvCO}_{2}, 36.9 \mathrm{~mm} \mathrm{Hg}\right.$; bicarbonate, $22.0 \mathrm{mmol} / \mathrm{l}$; and $\mathrm{BE},-2.5)$. Glucosuria was still present (100 mg/d $l$, determined by dipstick). On day 4 of hospitalization, the dog was discharged, although her appetite had not improved. After discharge, the dog was treated with the same regimen everyday at the local animal hospital. Three days after discharge, partial improvement in her appetite was observed, and glucosuria was completely resolved. Because mild azotemia remained, daily subcutaneous fluid therapy was continued. Three months after the initial administration, no clinical signs were observed. The CBC was normal. However, mild azotemia remained (BUN, $36.2 \mathrm{mg} / \mathrm{d} l$ and creatinine, $2.0 \mathrm{mg} / \mathrm{d} l$ ), resulting in chronic kidney disease. The urinalysis showed complete resolution of glucosuria. The urine amino acid analysis revealed that aminoaciduria was substantially, but not completely, improved (Table 1).

Renal tubular acidosis (RTA) has been classified into distal RTA and proximal RTA based on the anatomic location of tubular defect. Proximal RTA caused by impaired bicarbonate reabsorption in the proximal renal tubule is a characteristic of Fanconi syndrome. Proximal RTA typically causes hyperchloremic metabolic acidosis secondary to loss of bicarbonate, hypokalemia due to promoted potassium ex- cretion and acidic urine due to secretion of hydrogen ions in the distal tubule. In the dog, the presence of hyperchloremic metabolic acidosis, hypokalemia and acidic urine supported a diagnosis of proximal RTA. In conjunction with proximal RTA, glucosuria without hyperglycemia and generalized aminoaciduria indicated a generalized proximal renal tubular defect and confirmed the diagnosis of Fanconi syndrome.

In the dog, the urinary loss of most amino acids was increased, but not all amino acids, and derivatives were lost equally. Dogs with Fanconi syndrome typically have generalized aminoaciduria including acidic, basic and neutral amino acids. In a previous report, a dog with idiopathic Fanconi syndrome appeared to have increased excretion of amino acids with basic side chains, whereas those with acidic side chains (i.e., aspartic acid and glutamic acid) were less affected [18]. Interestingly, the dog in this report had no urinary loss of aspartic acid, and excretion of glutamic acid was elevated but not excessive. The differences may be related to defects in specific amino acid transport mechanisms depending on the underlying causes. In addition, the urinary concentration of taurine was reduced in the dog compared with that in normal dogs. A previous report indicated that urinary excretion level of taurine could be affected by the quantity of taurine and other components contained in ingested food [21]. The differences of urinary taurine concentration between the affected dog and control dogs may be related to the consumed diets.

The dog was fed different beef and chicken jerky treats daily, some of which contained ingredients from China. After symptom onset, much of her diet had been jerky treats for 1 month. After diagnosis of Fanconi syndrome, on the basis of the case history and extensive diagnosis testing, jerky treats were strongly suspected as the cause of Fanconi syndrome. Indeed, 1 week after their withdrawal, glucosuria was completely resolved, and the dog's appetite was gradually improved. After 3 months, there were no clinical signs, and aminoaciduria was substantially improved. According to the clinical course, jerky treats were eventually concluded to be the cause of Fanconi syndrome in the dog. Unfortunately, the specific product could not be identified as the causal component, because the dog had been fed several kinds of jerky treats. However, all jerky treats consumed by the dog could be commonly purchased in Japan. In fact, it should be noted that toxicosis associated with jerky treats can unsurprisingly occur in Japan.

The common clinical features of Fanconi syndrome associated with chicken jerky treats have been documented in previous reports $[11,20]$. The clinical signs observed in this case, including lethargy, anorexia, vomiting and weight loss, were similar to those observed in previous cases. Small breeds $(<10 \mathrm{~kg})$ appear to be mostly affected, accounting for $88 \%$. The dog in this report also weighed $<10 \mathrm{~kg}(5.4 \mathrm{~kg})$. This is likely because of the proportionally larger quantity of jerky treats consumed in small breeds. The period of time that jerky treats were fed prior to the onset of clinical signs ranged from 0.3 to 78 weeks in previous cases. Although the precise period of time that jerky treats were fed in this case was unknown, severe azotemia was documented 1 month 
after the onset of lethargy and anorexia. In this period, renal function appeared to be severely damaged, because of the increase in the quantity of jerky treats consumed. The dog continued to have mild azotemia 3 months after treatment, suggesting irreversible renal dysfunction. Indeed, despite the withdrawal of jerky treats, permanent kidney damage appears to occur in some cases, resulting in chronic renal disease [20]. A histopathological examination of the kidney in acute and chronic phases may be helpful to reveal the mechanism underlying renal damage.

At the time of writing, despite extensive investigations by the FDA, the specific causative substance has not been determined, and unfortunately, it could not be investigated in this report. In humans, degraded tetracyclines have been implicated as a cause of acquired Fanconi syndrome $[5,15]$. Recently, 6 illegal antibiotics, including trimethoprim, tilmicosin, enrofloxacin, sulfaclozine and sulfamethoxazole, have been detected in chicken jerky products for dogs [19]. However, there is no evidence indicating the relation between these antibiotics and the illness. Further investigations of the causative substance, including contaminating antibiotics and others, are warranted.

In conclusion, this is the first reported case of Fanconi syndrome following the consumption of jerky treats in Japan. For diagnosis of this disease, it is important to take a careful dietary history and perform urinalysis in dogs with nonspecific signs. If an association between the illness and jerky treat consumption is suspected, such treats should be immediately withdrawn, although irreversible renal dysfunction may remain. Veterinary clinicians should be aware of the toxicosis associated with jerky treats and report cases to regulatory authorities to prevent outbreaks.

\section{REFERENCES}

1. Appleman, E. H., Cianciolo, R., Mosenco, A. S., Bounds, M. E. and AI-Ghazlat, S. 2008. Transient acquired Fanconi syndrome associated with copper storage hepatopathy in 3 dogs. $J$. Vet. Intern. Med. 22: 1038-1042. [Medline] [CrossRef]

2. Bovée, K. C., Joyce, T., Blazer-Yost, B., Goldschmidt, M. S. and Segal, S. 1979. Characterization of renal defects in dogs with a syndrome similar to the Fanconi syndrome in man. J. Am. Vet. Med. Assoc. 174: 1094-1099. [Medline]

3. Brown, S. A., Rakich, P. M., Barsanti, J. A., Finco, D. R. and Kickbush, C. 1986. Fanconi syndrome and acute renal failure associated with gentamicin therapy in a dog. J. Am. Anim. Hosp. Assoc. 22: 635-640.

4. Carmichael, N., Lee, J. and Giger, U. 2014. Fanconi syndrome in dog in the UK. Vet. Rec. 174: 357-358. [Medline] [CrossRef]

5. Cleveland, W. W., Adams, W. C., Mann, J. B. and Nyhan, W. L. 1965. Acquired Fanconi syndrome following degraded tetracycline. J. Pediatr. 66: 333-342. [Medline] [CrossRef]

6. FDA. 2015. Questions and answers regarding jerky pet treats. Available at: http://www.fda.gov/AnimalVeterinary/Safety-
Health/ProductSafetyInformation/ucm295445.htm.

7. Finco, D. R. 1976. Familial renal disease in Norwegian Elkhound dogs: physiologic and biochemical examinations. Am. J. Vet. Res. 37: 87-91. [Medline]

8. Freeman, L. M., Breitschwerdt, E. B., Keene, B. W. and Hansen, B. 1994. Fanconi's syndrome in a dog with primary hypoparathyroidism. J. Vet. Intern. Med. 8: 349-354. [Medline] [CrossRef]

9. Green, C. E., Sykes, J. E., Brown, C. A. and Hartman, K. 2006. Leptospirosis. pp. 402-417. In: Infectious Diseases of the Dog and Cat, 3rd ed. (Green, C. E. ed.), Elsevier, St. Louis.

10. Hill, T. L., Breitschwerdt, E. B., Cecere, T. and Vaden, S. 2008. Concurrent hepatic copper toxicosis and Fanconi's syndrome in a dog. J. Vet. Intern. Med. 22: 219-222. [Medline] [CrossRef]

11. Hooper, A. N. and Roberts, B. K. 2011. Fanconi syndrome in four non-basenji dogs exposed to chicken jerky treats. J. Am. Anim. Hosp. Assoc. 47: e178-e187. [Medline] [CrossRef]

12. Major, A., Schweighauser, A., Hinden, S. E. and Francey, T. 2014. Transient Fanconi syndrome with severe polyuria and polydipsia in a 4-year old Shih Tzu fed chicken jerky treats. Schweiz. Arch. Tierheilkd. 156: 593-598. [Medline] [CrossRef]

13. Maldonado, J. E., Velosa, J. A., Kyle, R. A., Wagoner, R. D., Holley, K. E. and Salassa, R. M. 1975. Fanconi syndrome in adults. A manifestation of a latent form of myeloma. Am. J. Med. 58: 354-364. [Medline] [CrossRef]

14. Meyer, D. J. 1977. Temporary remission of hypoglycemia in a dog with an insulinoma after treatment with streptozotocin. Am. J. Vet. Res. 38: 1201-1204. [Medline]

15. Montoliu, J., Carrera, M., Darnell, A. and Revert, L. 1981. Lactic acidosis and Fanconi's syndrome due to degraded tetracycline. Br. Med. J. (Clin. Res. Ed.) 283: 1576-1577. [Medline] [CrossRef]

16. Noonan, C. H. and Kay, J. M. 1990. Prevalence and geographic distribution of Fanconi syndrome in Basenjis in the United States. J. Am. Vet. Med. Assoc. 197: 345-349. [Medline]

17. Rikitake, O., Sakemi, T., Yoshikawa, Y., Nagano, Y. and Watanabe, T. 1989. Adult Fanconi syndrome in primary amyloidosis with lambda light-chain proteinuria. Jpn. J. Med. 28: 523-526. [Medline] [CrossRef]

18. Settles, E. L. and Schmidt, D. 1994. Fanconi syndrome in a Labrador retriever. J. Vet. Intern. Med. 8: 390-393. [Medline] [CrossRef]

19. Sheridan, R., Mirabile, J. and Hafler, K. 2014. Determination of six illegal antibiotics in chicken jerky dog treats. J. Agric. Food Chem. 62: 3690-3696. [Medline] [CrossRef]

20. Thompson, M. F., Fleeman, L. M., Kessell, A. E., Steenhard, L. A. and Foster, S. F. 2013. Acquired proximal renal tubulopathy in dogs exposed to a common dried chicken treat: retrospective study of 108 cases (2007-2009). Aust. Vet. J. 91: 368-373. [Medline] [CrossRef]

21. Tôrres, C. L., Backus, R. C., Fascetti, A. J. and Rogers, Q. R. 2003. Taurine status in normal dogs fed a commercial diet associated with taurine deficiency and dilated cardiomyopathy. J. Anim. Physiol. Anim. Nutr. (Berl.) 87: 359-372. [Medline] [CrossRef]

22. Tsai, M. Y., Marshall, J. G. and Josephson, M. W. 1980. Free amino acid analysis of untimed and 24-h urine samples compared. Clin. Chem. 26: 1804-1808. [Medline] 